\title{
Comparison Between Atlas in Xinjiang of China and Patola in Gujarat of India
}

\author{
Weizhu $\mathrm{An}^{1}$, Sudha Dhingra ${ }^{2}$ \& Feng Zhao ${ }^{1,3}$ \\ ${ }^{1}$ School of Fashion and Art Design, Donghua University, Shanghai, China \\ ${ }^{2}$ National Institute of Fashion Technology, New Delhi, India \\ ${ }^{3}$ China National Silk Museum, Hangzhou, China \\ Correspondence: Sudha Dhingra, National Institute of Fashion Technology, New Delhi, India. Tel: \\ 91-98-1854-9510. E-mail: sudha.dhingra@nift.ac.in
}

Feng Zhao, China National Silk Museum, Hangzhou, China. Tel: 86-139-5806-6182. E-mail: 1007043621@qq.com

Received: December 16, 2019

Accepted: December 28, 2019

Online Published: January 31, 2020

doi:10.5539/ass.v16n2p45

URL: https://doi.org/10.5539/ass.v16n2p45

\begin{abstract}
Ikat is an ancient technique by which colored patterns are formed by tying and dyeing threads before they are woven. Ikat is an ancient resist dyeing technique in which the yarns are tied and dyed according to a specific pattern prior to weaving. This paper focuses on Atlas and Patola, the most famous ikat fabrics in China and India respectively as the research objects. The effort is to provide comparative analysis from the aspects of weaving technology, pattern style, composition characteristics and colors, based on literature and images. Although they are similar in production process, they have very different characteristics due to cultural background, religion, environment and aesthetic tastes of consumers and weavers. Both textiles showcase the local plants, flowers and colour preferences. Islam influences Atlas textiles and hence without animal and figurative pattern. Patola has different patterns for consumers from different religious following. Atlas and Patola are the fabrics of inheritance and represent two different regions and cultures.
\end{abstract}

Keywords: China, India, Ikat, Atlas, Patola, Patterns, and Comparison

\section{Introduction}

The ancient technique Ikat, whose name comes from Malay words meaning 'to bind', generally owns three different styles: warp ikat, weft ikat and double ikat. The ikat fabrics are characterized by hazy or blurred edged patterns on the textiles due to the dye infiltration in the process of silk or cotton dyeing. These textiles are currently produced in Xinjiang and Hainan in China; Gujarat, Andhra Pradesh and Orissa in India; and in Japan, Uzbekistan and Southeast Asia. In each region, ikat textiles are known by different names.

Atlas and Patola are representatives of ikat in China and India. The study of the origin of these two has always been controversial. In the sixth century A.D. on the wall paintings of Ajanta in India, the image of ikat appeared in a woman's dress. Although there was no physical appearance, many scholars believed that ikat originated in India, and then spread all over Asia and Europe along the land and sea routes (Okamura, 1984), while some scholars believed that ikat originated in Central Asia. Atlas, the ikat produced in Xinjiang, China, is more closely related to Central Asian ikat in terms of scale and colours. It should be spread from Central Asia (Zhao, 2019). Professor Xu Hong of Xinjiang University has done the most deep and profound research in this field (2015, 2017). In recent years, the research on India's Potola is mainly from the perspective of pattern innovation and application in fashion. Through the comparative study of the most famous ikat i.e Atlas from China and Patola from India, an effort is being made to understand the technology in both the regions and hence reference for the protection and development of ikat in both the countries.

\section{The History of Atlas and Patola}

The earliest tie-dyed fabric in China is from the Tang Dynasty (618-907) in Qinghai (Figure 1). At the end of the 12th century, Altas was mentioned in the historical materials of the 16th century, but there is no evidence that the technology of ikat existed in Xinjiang, Central Asia and India before the 19th century. The earliest piece of ikat 
in Victoria and Albert Museum is dated back to 1870 and is from Kabul, Afganhistan. The earliest reference of Atlas in China is in the collection of Palace Museum in Beijing, which is dated as middle and late Qing Dynasty (around 1820) (Figure 2). These textiles and its production methods were introduced from Uzbekistan in Central Asia to the people in Hotan Area in the south of Xinjiang, which was favored by the Turkic Uighur people. These ikat textiles are traditional silk fabrics, which are still being made in the region.

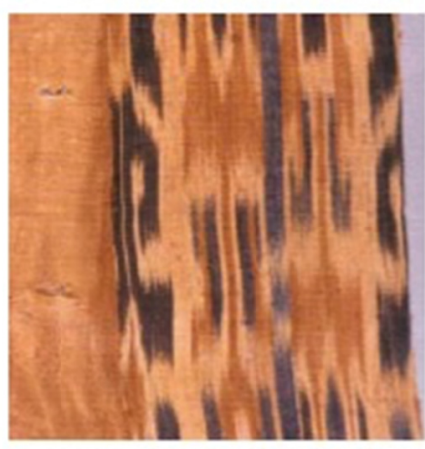

Figure 1. Ikat in Tang Dynasty

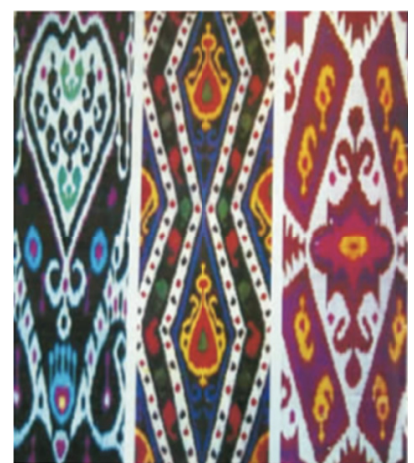

Figure 2. Atlas in Xinjiang

In India, the double ikat fabrics from Gujarat are known as 'Patola'. There is no clear record of the origin of Patola. The term 'Patola' first appeared in Indian Gujarati's literature of the 12th century. The earliest reference of ikat in India was found on cave paintings of Buddhist Ajanta in the $6^{\text {th }}$ century AD. The similar design of ikat are also found on the females' dresses which are portrayed on Ajanta murals. Moreover, the double ikat are exactly mentioned in the couplets of Rani Ranakdevi, Gujarati literature in the $11^{\text {th }}$ century AD, and recorded by European Travelers in the $16^{\text {th }}$ century AD.

However ikat textiles were exported to the Malay islands as religious cloth in the 13th century, and then to China and Japan. An early Patola, appeared on the frescoes of Mattancheri and Padmanabhapuram in Kerala, South India in the 16th-17th century. At the beginning of the 16th century, the word 'Patola' appeared in many European travel notes and records of the East India Company, and during the $16^{\text {th }}-17^{\text {th }}$ centuries, patolas were regarded as precious silks and important trade items by South-east Asia and Europe. Then it got very popular in South India during the $17^{\text {th }}-18^{\text {th }}$ centuries.

The ikat textiles produced by weavers in Salvi community adopt expensive silk yarns. Patolas were previously manufactured in Ahmedabad, Surat, Patan, Khambat, Surat, Porbander and Baroda in Gujarat. At present, the ikat textiles are produced only in Patan and Baroda in Gujarat, India.

\section{A Comparison of Production Technique of Atlas and Patola}

Ikat is generally classified into three categories:

- Single ikat: There are two types of single ikat namely warp ikat and weft ikat. As its name suggests, in warp ikat, the warp yarns are tie-dyed and woven with plain solid coloured weft yarns, similarly in weft ikat, the weft yarns are tie-dyed and woven with plain warp yarns.

- Double ikat: In double ikat, both warp and weft yarns are tie-dyed according to a pre-determined pattern, then woven to create clear designs on fabric.

- Combined ikat: In combined ikat, both warp and weft yarns are tie dyed but presented in selected areas of a textile, to create interesting patterns.

Atlas Ikat of Xinziang is usually $40 \mathrm{~cm}$ in width and is used for women's clothing. Silk is used as the raw material. There are two kinds of warp yarns- twisted as well as untwisted. Silk and cotton blends are also used for making these warp faced ikats. Instead of winding the warp yarns on the warp beam, at the end of the loom, near the warp beam, stone weights are used to pull the warp. The structure of Atlas is comparatively complex as it includes plain, twill and satin weave. Satin weave is manipulated in many different combinations by using 4,6 , 8 or 12 harnesses. In Qing Dynasty, Atlas ikat were made in plain and twill weave (3/1), and then to plain weave and twill weave in 1920s. After 1949, these are made using 6-harness satin. The organizational structure of Atlas is closely related to the development of loom. But now treadle looms are used to weave plain and twill fabrics $(3 / 1)$.

Indian Ikat Patola is mainly used as saris, shawls, headscarves or fabrics. Patola sarees are considered to be auspicious and are worn on very special occasions, especially like weddings and festivals. Moreover the textile 
was also used as temple hangings and offered to the divinity in the past.

The royalty while performing religious or ritualistic ceremonies wore the patola fabric. In the 13th century, these textiles were exported to Indonesia in large quantities as a religious product and was also popular among the upper class.

Patola is woven in plain weave on a simple two-harness loom with no rigid frame (Figure 4). Generally pure silk is used for weaving patolas. The Patola ceremonial cloth exported to Southeast Asia uses cotton thread in the border.

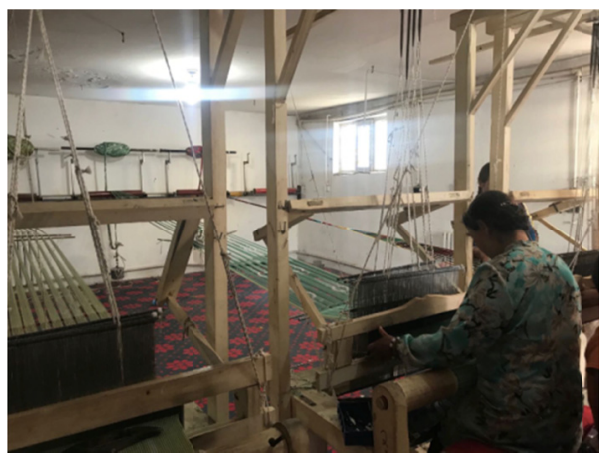

Figure 3. Treadle Looms

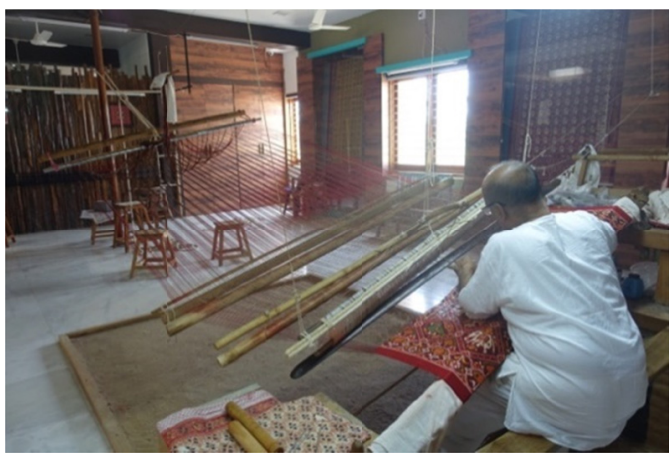

Figure 4. Single Harness Looms

The process of producing double ikat fabrics costs lots of time and intensive labours. And its design should be planned very carefully since both warp and weft yarns are tie-dyed repeatedly in order to introduce multiple colours. After the yarns are tie-dyed, the warp and weft are woven to plain weave. The weaving of Atlas and Patola goes through the following Process: warping, binding (warp and/or weft), dyeing, and weaving. First of all, the warps are arranged into bundles and fixed on the shelves according to the required length. Before dyeing, a pen is first used to mark the areas of a pre-designed pattern on the warps. In Xinjiang, corn husk was used to resist the yarns. At present, light, thin and soft plastic film is used to bind, which is easy to tie and has good dye resistance. Hence the patterns are clearly resisted and result in sharp edged motifs.

In India, cotton yarns are used for resisting the bundled yarns. It is ensured that the binding is tight so that dyes do not penetrate to the resisted areas. After the first color is dyed, the yarns are retied as per the design. This step will be repeated many times till all the colours are dyed as per required design. The process of sequential dyeing is similar in both textiles. There is a subtle difference in the use of tools, but the process remains same.

\section{Comparison of Art Feature}

\subsection{Motifs}

The patterns on Atlas ikat are derived from life around the weavers and hence include plants, utensils and geometric forms seen in nature. There are very few forms of animal and humans because the doctrine of the Koran in Islam does not permit depiction of these. However, some pictographic patterns such as the appearance of sheep horns are seen in Atlas ikat. The plants include fruits and flowers such as almond (Figure 5(a)), pomegranate, apple, pear etc, which are found in abundance in Atlas ikats. Almond wood pattern is the most common pattern in Atlas, as it is believed to have the therapeutic effect of curing diseases and strengthening the body and hence represent health and longevity. The crescent moon in Islam is regarded as sacred and is used by the Chinese Uighur people, usually in combination with curly grass patterns. Pomegranate (Figure 5(b)) means vitality, which has always been regarded as a symbol of having many children. Utensils mainly include the local musical instruments, wooden comb, sheep horn, sickle, etc. Duerta (Figure 5(c)) is a very famous two string instrument of the region. Besides its function as a musical instrument, it is also often displayed as a handicraft, expressing Xinjiang peoples keen love to life. Tassel pattern (Figure 5(d)) is not the main pattern, but often appears in the lower part of other patterns, used for connecting two patterns and filling the gap. Animals are symbols of bravery. As the Islamic doctrine does not allow the depiction of animals and people, abstract horn patterns are used on Atlas to express the worship of male power and ancestors. There are rhombus, stripes, ellipses, mountains and many such patterns. The mountain shape is the abstract generalization of Tianshan Mountains and Kunlun Mountains in Xinjiang. These patterns do not appear alone and are used in combination with other patterns. 


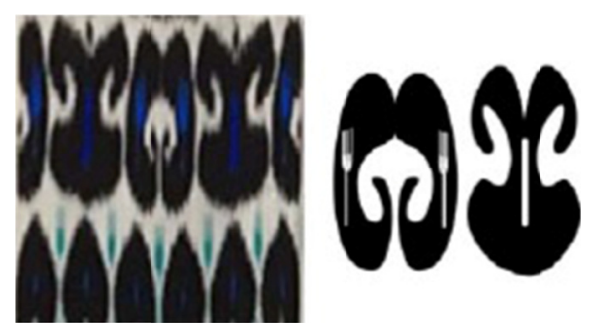

(a) almond
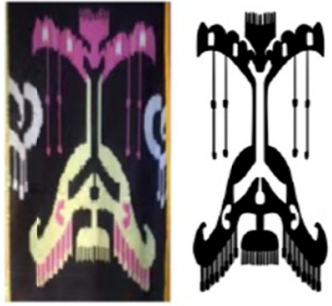

(c) Duerta

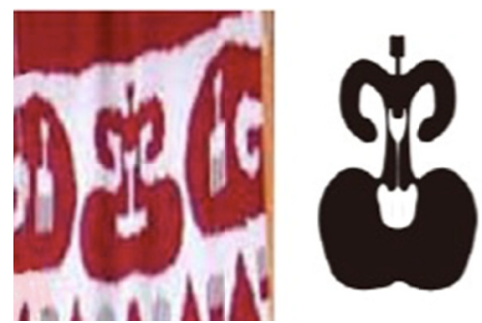

(b) Pomegranate

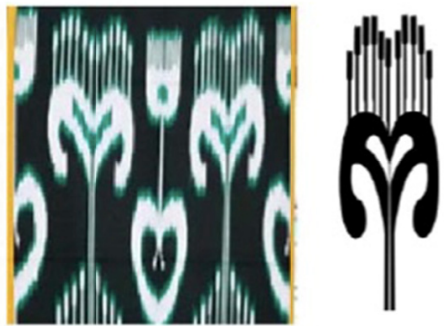

(d) Tassel pattern

Figure 5. Classical pattern of Atlas (these patters from Zhang Xiaoxia's artical)

The designs in Indian Patola can be be categorized into four - Designs inspired from plants, flowers, animals and geometrics. Influenced by many religions and customer choices, the patterns of Patola are different for saris and fabrics. Traditional designs of leaf (pipal) on Patola saris were mainly used by women of Hindu Brahmin and Jain communities in Gujarat (Figure 6). The Muslim women preferred the geometric and non-figurative patterns, as allowed by their religion (Figure 7). Another preferred patola is with patterns such as dancing girl, elephant, parrot, pipal leaf with a double outline, and flowers on a crimson or rich red or orange background. Dancing girl symbolizes celebration; elephant symbolizes strength and knowledge and parrot is a symbol of prosperity and peace. These designs were also exported to Southeast Asia (Figure 8).

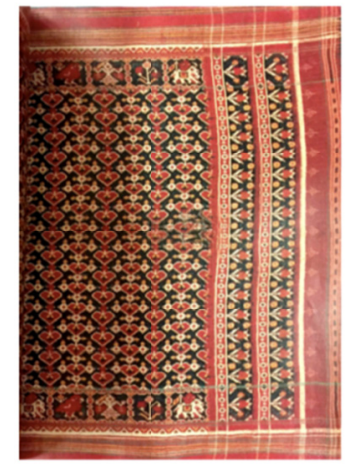

Figure 6. Pipal design

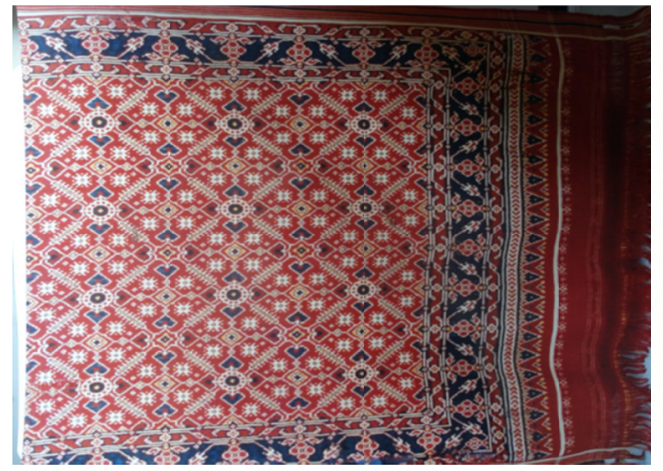

Figure 7. Geometric design

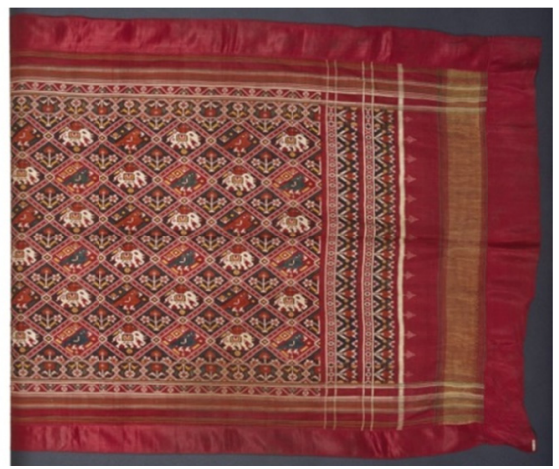

Figure 8. Animal design

\subsection{Forms}

The design form of Atlas ikat is of balance and rhythm without leaving blank. Double-square continuity pattern and four-square continuity pattern are the main composition forms, which give a sense of rhythm and implies longevity.

Dynamic geometrical grid patterns and intricate stylized motifs combine to form one of the most fabulous double ikat textiles of India. The entire vocabulary of Patola design is derived from the square or rectangular unit, there are usually filled with flower and animal patterns in the diamond structure. According to the use, there are different types of composition of Patola, but they are all composed of central pattern, edge decoration and pallav. The distribution of patterns is primary and secondary. The central pattern is composed of rhombus structure and quadrilateral continuity, which combines the geometric grid and pattern. 


\subsection{Colors}

Over the years, the colour of Atlas ikat changes from mineral and plant dyes to chemical dyes. Influenced by various religions and Central Plains culture, Atlas' colors (Figure 9) are gorgeous, bold and exaggerated, with red, yellow, blue and green as the main colors. Uighur people practised Buddhism, Shamanism and worshiped fire before they converted to Islam. They believed that fire has special power and regarded the colour red, which represents fire, as mysterious and auspicious. Red is mostly used in silk clothing. Yellow is a very noble color in ancient times, as there is a large area of desert in Xinjiang people's region. Blue colour is a metaphor of blue sky and a yearning for free life. Green is the color of life in Islam and is the color of oasis and plants in the desert and hence symbol of life and hope. Muslims regard white as the holy color, hence white headscarf robe is the symbol of Arabs.
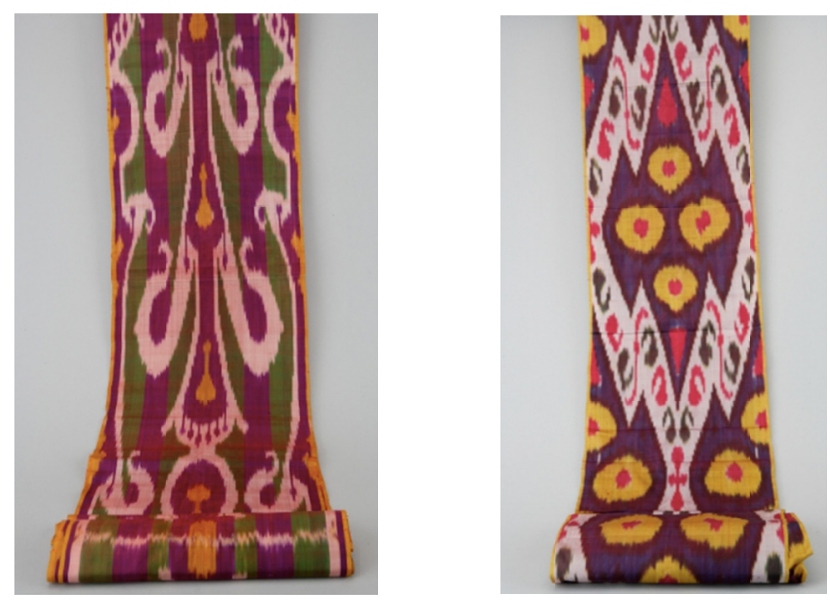

Figure 9. Atlas

Intense colours are adopted in Patola textiles, like bright red, golden yellow, green, dark blue, reddish brown etc. Red as the ground, white and other colors are used in patterns.

\section{Conclusion}

Atlas and Patola are outstandingly beautiful ikat textiles of China and India. Although they use the same technique of tie and dye, they have different characteristics under the influence of different religions, cultural backgrounds, local people's living environment and aesthetic tastes. Patolas are single or double ikat in plain weave, whereas Atlas is single ikat in satin or twill weave, made in warp faced ikat technique. In both the textiles, patterns come from real life, mainly plants, flowers and geometrics. However, Atlas is influenced by Islamic culture, and there are no figures of animals or people. Patola were exported to Southeast Asia, with the theme of elephants, lions, parrots and dancers according to the different users. There are complete flower patterns used by Muslims. Brahmin and Jain communities used the decoration of animals with Pipal leaves as the main pattern. In terms of composition and form, both exhibit an essence of balance and symmetry. Atlas is a repeated and continuous arrangement of patterns, and the composition form of Patola is distinct in primary and secondary. In terms of color, Atlas is influenced by religion, and its color is rich and gorgeous. In India, the main color is red, which is relatively stable, and the color combinations are traditional. These textiles are the products of the integration and exchange of ikat and local culture in different regions, representing the highest technology of ikat in China and India. The study of the two can provide reference for each other's inheritance and development.

\section{Acknowledgments}

This work was supported by a project: the Fundamental Research Funds for the Central Universities (2232019G-08). The authors would like to thank Professor Feng ZHAO and Sudha Dhingra for critically reviewing the manuscript, and to the editor and the readers of Asia Social Science.

\section{References}

Fraser, L. S. (1988). Hand-woven Textiles. Oxford: Oxford University Press.

Gillow, J. (1993). Traditional Indian Textiles. London: Thames and Hudson.

Gillow, J., \& Sentance, B. (2001). World Textiles. London: Thames \& Hudson Ltd. 
Hou, S. X., \& Wang, B. (2011). Atlas in Hetian. Suzhou: Suzhou University Press.

Liu, Y. (2010, September). A textual study of the history and legend of "Atlas" (pp. 29-31). Kashi: Kasha Normal Journal.

Lou, S. Q. (1998, June). Adlys Silk and Hetian Loom of Xinjiang (pp. 43-45). Hangzhou: Silk.

McLuhan, M. (1970). From cliche to archetype. New York, NY: Viking Press. https://doi.org/10.1007/978-1-349-11502-0_9

Murphy, V., \& Crill, R. (1991). Tie-dyed Textiles of India: tradition and trade. London: Victoria and Albert Museum.

Xu, H., Tong, Z. Y., \& Zhang, Yu. (2017). Decoration patterns of Aidelaisilk (pp. 69-74). Hangzhou: Silk. https://doi.org/10.3969/j.issn.1001-7003.2017.05.012

$\mathrm{Xu}$, X. G. (2006). Western China and the eastern and western civilization. Beijing: Yanshan Publishing House.

Yuan, X. P. (1991, December). Study on Ancient Ikat Silk in China. Hangzhou: Silk.

Zhang, T. J. (2019, June). On the origin of Xinjiang Atlas from the perspective of Ikat in Central Asia (pp. 51-56). Beijing: Design Research.

Zhang, Y. Z., \& Lan, S. (2006). History of fiber art. Beijing: Tsinghua University Press.

\section{Copyrights}

Copyright for this article is retained by the author(s), with first publication rights granted to the journal.

This is an open-access article distributed under the terms and conditions of the Creative Commons Attribution license (http://creativecommons.org/licenses/by/4.0/). 